\title{
The diversity and activity patterns of wild felids in a secondary forest in Peninsular Malaysia
}

\author{
J. Mohd. Azlan and Dionysius S. K. Sharma
}

\begin{abstract}
Abstact A study to describe the diversity of wild felids was carried out in Jerangau Forest Reserve, Ulu Terengganu, Malaysia, using camera traps, over a period of 21 months. A total of 24 camera traps were used, with a total of 5,972 trap days. Six species of wild cats in five genera were recorded: tiger Panthera tigris, leopard Panthera pardus, clouded leopard Neofelis nebulosa, leopard cat Prionailurus bengalensis, golden cat Catopuma temminckii and marbled cat Pardofelis marmorata. This represents all but two of the felid species known to occur in Peninsular Malaysia. The use of camera traps provided detailed information on the occurrence and activity patterns of
\end{abstract}

these relatively secretive mammals. The most frequently photographed species was tiger (38.5\% of records) followed by leopard (26.3\%) and leopard cat $(21.9 \%)$. The presence of charismatic flagship species such as tiger in this unprotected lowland dipterocarp secondary forest will be of help to local conservation organizations and the Wildlife Department in any proposals for the protection of these areas.

Keywords Camera trapping, Catopuma, disturbed forest, Malaysia, Neofelis, oil palm estate, Panthera, Pardofelis, Prionailurus.

\section{Introduction}

Peninsular Malaysia contains $72 \%$ of the wild cat diversity of tropical Asia, with seven species in five genera: tiger Panthera tigris, leopard Panthera pardus and clouded leopard Neofelis nebulosa, the smaller leopard cat Prionailurus bengalensis, flat-headed cat Prionailurus planiceps and marbled cat Pardofelis marmorata, and the intermediate sized golden cat Catopuma temmincki (Medway, 1983; Lim, 1999, 2002). A further species, the fishing cat Prionailurus viverrinus, is considered rare in Peninsular Malaysia (Nowell \& Jackson, 1996) and the only potential recent record is from Taman Negara National Park (Kawanishi \& Sunquist, 2003). Although these seven species occur throughout Peninsular Malaysia (Medway, 1983; Lim, 1999), their abundance and local diversity has been little studied in this region due to their cryptic behaviour and the shortage of resources and expertise for research. Most research has concerned tigers (Ellagupillay, 1984; Khan, 1987; Topani, 1990; Jasmi, 1998; Kawanishi, 2002).

These felid species, except for the fishing cat, are listed under schedule one of the Protection of Wildlife Act 1972, under which hunting and trade are prohibited.

J. Mohd. Azlan (Corresponding author) Faculty of Resource Science and Technology, University Sarawak Malaysia, 94300, Kota Samarahan, Sarawak, Malaysia. E-mail amazlan@frst.unimas.my

Dionysius S.K. Sharma WWF Malaysia, 49, Jalan SS23/15, Taman SEA, 47400 Petaling Jaya, Selangor, Malaysia.

Received 21 April 2004. Revision requested 9 September 2004. Accepted 7 March 2005. First published online 19 January 2006
However, under certain circumstances of conflict, individual animals can be eradicated and the action reported to the Department of Wildlife and National Parks under section 55 of the Wildlife Act 1972. Tiger is categorized as Endangered on the IUCN Red List (IUCN, 2004), and clouded leopard, flat-headed, marbled, golden and fishing cats as Vulnerable.

Approximately $45 \%$ of the total land area of Peninsular Malaysia is covered by forest, including selectively logged and otherwise secondary forest. However, only 1.6 million ha, c. $20 \%$ of the forested area, is designated as protection forest. Currently, Peninsular Malaysia has 0.74 million ha of national parks and other wildlife conservation areas (Anon, 2000). With the rapid destruction of natural habitats (Jackson, 1983) it is important to document the presence, diversity and distribution of felids in the various forest patches to facilitate monitoring and conservation programmes and to focus management efforts.

A camera trapping programme to determine the relative abundance of tigers and potential prey species in Peninsular Malaysia (Mohd. Azlan \& Sharma, 2001) provided extensive data on the occurrence of other felid species. Using this data our aim is to discuss the diversity, relative abundance and activity patterns of felids and to provide baseline data to facilitate the conservation of these species in secondary forest in Peninsular Malaysia.

\section{Study Area}

The study was conducted in Jerangau Forest Reserve $\left(140,000\right.$ ha; $\left.4^{\circ} 55.5^{\prime} \mathrm{N}, 103^{\circ} 5.7^{\prime} \mathrm{E}\right)$, which surrounds 
FELDA Jerangau Barat, an oil palm scheme in the State of Terengganu. The oil palm scheme was established in 1972. The total area of the scheme is 2,109 ha, within which the plantation area is 1,827 ha, with 363 families of settlers and an oil palm refinery. The surrounding forest consists mainly of selectively logged hill dipterocarp and lowland dipterocarp forest at altitudes of 20-538 $\mathrm{m}$ that receive an average total annual rainfall of c. $2,000 \mathrm{~mm}$. The vegetation composition of these forest types has been described by Symington (1974) and Whitmore (1975). Past logging has resulted in disturbed forest with dense undergrowth, particularly in the area of forest to the south of the plantation, with dense stands of the invasive ferns Dicranopteris sp. and Gleichenia sp. in abandoned log yards and along old logging roads. Dense undergrowth and shrubs with mosaics of pioneer tree species such as Macaranga sp. also occur in some parts of the forest. Forest gaps are frequent in recently logged forest, whereas the sub-canopy is relatively intact in secondary forest (i.e. previously logged areas). Some areas in the north and south of the forested areas surrounding the study site were logged for the second cycle (logging cycles are now typically at 33 year intervals), from 2000 to 2002, during our study. Despite the disturbance from past and recent logging operations at the Reserve, the forest to the north and south of the plantation still contains extensive stands of mature dipterocarp trees.

\section{Methods}

Cam Trakker passive camera trap units (Camtrak South, Watkinville, USA) were used. The time delay between photographs was set to a minimum of 3 minutes. All cameras were operational 24 hours per day except in instances of malfunction or damage caused by elephants. Time and date were automatically recorded for each exposure except during camera malfunction, technical errors or excessive moisture on the film due to high humidity and condensation.

Cameras were deployed in 24 locations, c. $1.8-2.2 \mathrm{~km}$ apart, surrounding the oil palm estate. Six locations were along the plantation-forest edge and 18 were in secondary forest. All camera units were mounted on trees, 2.5-3.5 $\mathrm{m}$ from a path or trail, with the infrared beam set $c .50 \mathrm{~cm}$ from the ground. Most of the trails and paths were old logging roads with thick undergrowth of secondary trees and shrubs.

Cameras were checked every month to load new film. There were, however, several instances where the films had been fully consumed before checking, so there could be gaps in the records. The same camera locations were maintained throughout the duration of the study, from February 2000 to October 2001. Cameras were only removed or relocated to accommodate changing local conditions such as tree fall, dense undergrowth, and disturbance by elephants or inundation by rainwater. The trapping effort at each camera-trap site was not, therefore, identical.

Total number of trap nights was calculated as $\sum_{i=1} t n_{i}$ where $i$ is a trap location and $t n$ is a trap night at the $i$ th location. The relative abundance index $(R A I)$ for each species was calculated as $R A I=\sum_{i=1} d_{i} 100 / \sum_{i=1} t n_{i}$, where $i$ is a trap location and $d$ is a detection of the species at the $i$ th location (Kawanishi et al., 1999). The index is calculated to reflect the relative abundance of felids based on the following untested assumptions: (1) there is a monotonic relationship between $R A I$ based on the photographic rates and the actual abundance of species, and the uncertainty associated with the relationship is negligible; (2) all felid species have equal chance of being recorded by the camera traps; (3) the probability of detection remains unaffected by temporal and spatial variables. The variance of $R A I$ could not be calculated due to lack of replication, and therefore it was assumed to be negligible. The RAI provides an estimate of abundance based on total number of photographs and effort, and hence facilitates comparisons between different sites and studies.

Each photograph was printed with its date and time. Any that did not contain this information were excluded from the analysis. We assumed that the numbers of photographs taken were correlated with felid activity levels (Kawanishi, 2002). Time periods were pooled in 1 hour intervals, and activity level of a species was measured by the percentage of the total qualified photographs. Nocturnal activity was categorized as being from 19.00 to 05.00 .

Only tigers were individually identified, based on the pattern on the left side of the body (Schaller, 1967; McDougal, 1977; Karanth, 1995; Karanth \& Nichols, 1998), obvious morphological distinguishing features, and body dimensions (Franklin et al., 1999). Photographs of the right side of tigers and photographs of poor quality, totalling 58, were excluded from the analysis.

\section{Results}

A total of 3,314 photographs were exposed, of which $67 \%$ were wildlife photos. Species could not be determined in $16 \%$ of the photographs due to poor focus or angle. Approximately $1 \%$ of the total photographs were damaged by elephants, who crushed eight camera units; these cameras were replaced, in new locations, during the study. A total of 2,121 wildlife photos, $64 \%$ of the total, were usable, equivalent to 88.4 photographs per camera deployed. The total sampling effort was 5,972 camera trap days over 21 months. All the felid photographs were of single individuals except for two adult tiger recorded in a single exposure on two occasions at one site. A total 
of 392 photographs of felids were obtained. Tiger was the most common species recorded $(R A I=2.53)$, and marbled cat the rarest, with only a single photograph $(R A I=0.02$; Table 1$)$.

The photographs represented five genera and six species of felid (Table 1). The flat-headed and fishing cats, which are strongly associated with wetlands (Medway, 1983; Nowell \& Jackson, 1996; Kawanishi \& Sunquist, 2003), were not detected despite the fact that four cameras were set c. $400 \mathrm{~m}$ from small streams. The felid species accumulation curve reached a plateau after 7 months (Fig. 1), suggesting that additional efforts at similar sites may not record further species.

All the recorded felids exhibited at least two peaks in their daily activity pattern (Fig. 2). Records were predominantly at dawn and dusk and during the night, with relatively few records during the daytime.

\section{Discussion}

A minimum of 12 individual tigers were identified, and in addition three individual tiger cubs (c. 11-12 months old) were recorded, in the first few months of camera trapping. However, only one cub was tracked to the subadult stage, near the end of the fieldwork. The high relative abundance of tigers in this area could possibly be due to ongoing logging activities, which may have caused the animals to disperse from surrounding forest (Mohd. Azlan \& Sharma, 2003). In addition, the availability of livestock such as cattle may also have attracted them to the area. At least 60 cattle were confirmed killed by tigers from March 2000 to July 2002 in the oil palm estate (Mohd. Azlan \& Sharma, 2001). Tiger mostly depredated livestock at dusk and dawn, even though cattle roam freely throughout the day in the oil palm plantation and near the forest fringe.

Of the recorded species leopard showed the highest percentage $(70.43 \%)$ of diurnal activity. Similarly, Rabinowitz (1989) found that an adult male leopard was largely diurnal (66\% of daily activity) when tiger was present, suggesting that leopard tend to be more diurnal when tigers occur in the same area. Kawanishi \& Sunquist (2004) recorded a higher relative abundance of leopard (150 camera-trap photographs) with a low relative abundance of tigers (61 photographs), suggesting that leopard could be more terrestrial than arboreal

Table 1 Number of camera-trap photographs, relative abundance index (see text for details), percentage of camera-trap photographic records and percentage nocturnal activity of felid species recorded in Jerangau Forest Reserve.

\begin{tabular}{lllll}
\hline Species & $\begin{array}{l}\text { Total } \\
\text { photographs }\end{array}$ & $\begin{array}{l}\text { Relative } \\
\text { abundance index }\end{array}$ & $\begin{array}{l}\text { Percentage of } \\
\text { records (\%) }\end{array}$ & $\begin{array}{l}\text { Nocturnal } \\
\text { activity (\%) }\end{array}$ \\
\hline Tiger Panthera tigris & 151 & 2.53 & 38.5 & 62.50 \\
Leopard Panthera pardus & 103 & 1.72 & 26.3 & 29.57 \\
Leopard cat Prionailurus bengalensis & 86 & 1.44 & 21.9 & 77.14 \\
Golden cat Catopuma temnickki & 38 & 0.64 & 9.7 & 48.00 \\
Clouded leopard Neofelis nebulosa & 13 & 0.22 & 3.3 & 75.00 \\
Marbled cat Pardofelis marmorata & 1 & 0.02 & 0.3 & 100 \\
Total & 392 & 6.56 & & \\
\hline
\end{tabular}

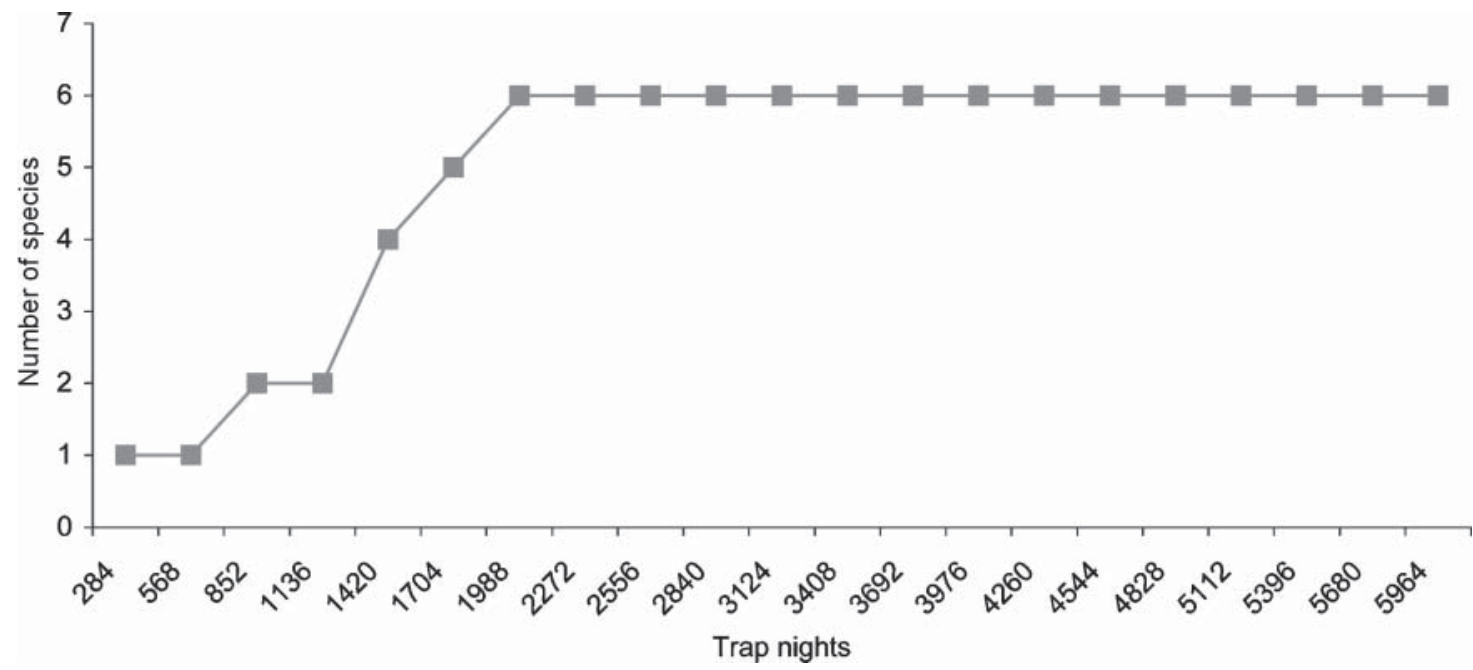

Fig. 1 Cumulative number of felid species captured in camera trap nights from February 2000 to October 2001 at Jerangau Forest Reserve. 

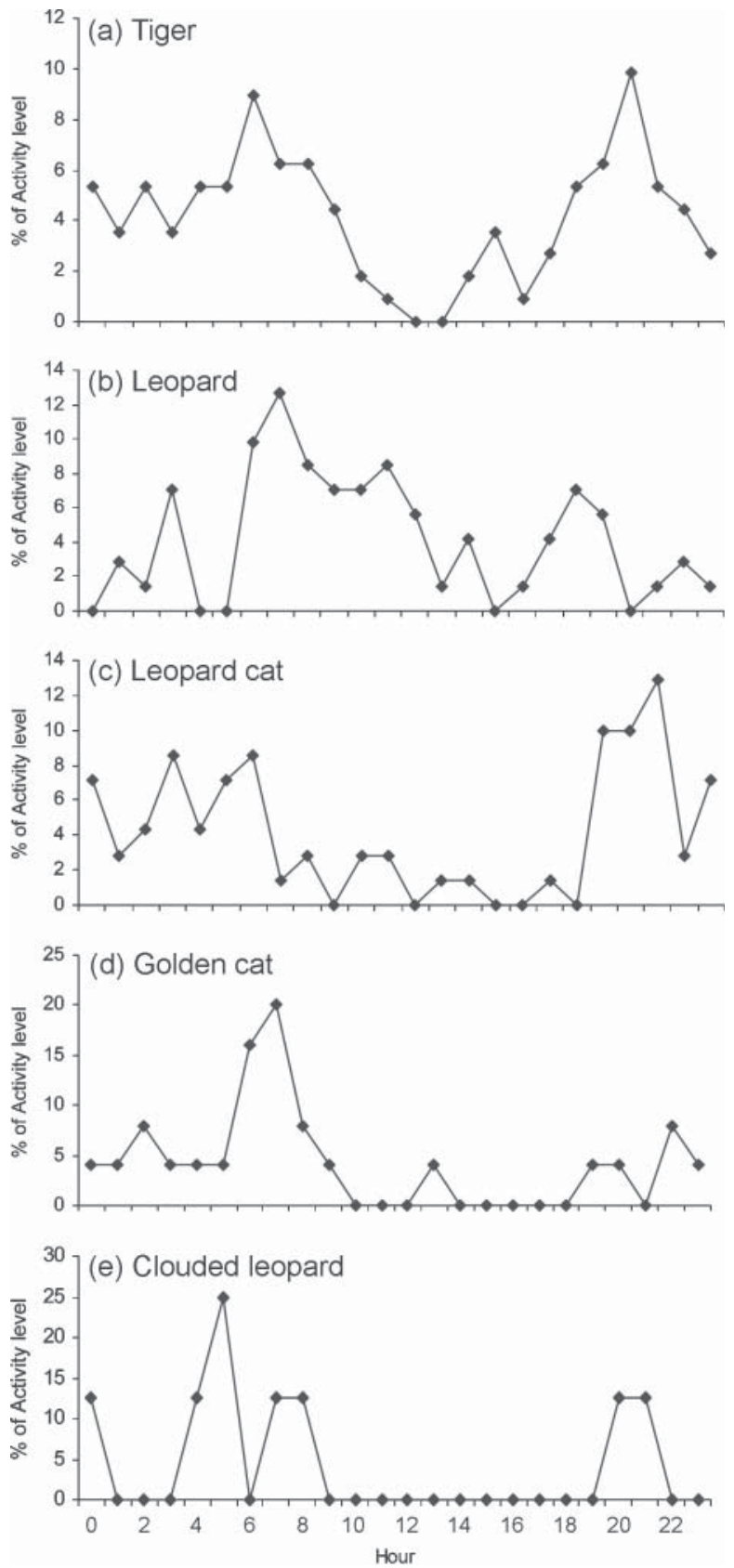

Fig. 2 Activity levels (\%) of tiger, leopard, leopard cat, golden cat and clouded leopard based on pooled camera trapping records in Jerangau Forest Reserve from February 2000 to October 2001. Note the different scalings of the vertical axis.

when tigers have low activity levels. Tigers and leopards avoid competition by hunting with different activity patterns and in different vegetation strata, as well as on different prey species (Seidensticker, 1976). In our study, however, leopard utilized the same areas, and frequently the same trails as tigers, suggesting there is considerable overlap in habitat use.
Tigers may use wide and established trails for movement (Kawanishi, 2002) but small and intermediate-sized felid species may avoid larger felids or other large mammals on the same trail by having different activity patterns or otherwise avoiding them. There could therefore be strong differentiation in the selection of prey species and habitat among some of these felid species (Seidensticker, 1976) and inter-specific competition will be consequently reduced.

A higher relative abundance of leopard cats was recorded near the forest edge $(R A I=0.92)$ than in interior secondary forest $(R A I=0.52)$, suggesting that this species readily utilizes the oil palm estate to hunt for its rodent prey (Lim, 1999). Kawanishi (2003) also noted fewer records in interior forest compared to forest edges. The maintenance of pockets of forest in and adjacent to plantations provides shelter, habitat diversity (Rajanathan, 2000) and a pool of prey species for leopard cats (Rajaratnam, 1999). Despite having a markedly crepuscular activity pattern (Fig. 2) leopard cat was also occasionally recorded during the day. This could be explained by the non-specificity of its diet; its prey species consist of both nocturnal and diurnal animals (Lim, 1999).

Marbled cat was relatively more common in our study than reported by Medway in Peninsular Malaysia (1983). This species appears to be active both diurnally and nocturnally, with $52 \%$ of the photographic records being diurnal, including some records at midday. Its typical prey includes both diurnal and nocturnal species (Nowell \& Jackson, 1996; Lim, 2002).

Little is known about the ecology of clouded leopard and marbled cat but their low relative abundance during this study suggests that these species could be rare in the study area or inactive on the ground. These species are arboreal for a substantial amount of the day and thus they are not necessarily recorded in camera traps in proportion to their abundance (Payne et al., 1985; Nowell \& Jackson, 1996). Thus their relative abundance could be underrepresented in our results.

The flat-headed cat is reported to occur in disturbed primary and secondary forest as well as in oil palm plantations (Sunquist \& Sunquist, 2002; Bezuijen, 2003) but was not recorded in our study. This species was also not recorded in primary forest of Taman Negara National Park (Kawanishi et al., 1999; Kawanishi \& Sunquist, 2004). It is possible that flat-headed cat do not use open trails, frequented by the larger mammals, where all the cameras were set. It is unlikely that this species passed through the camera traps without initiating the sensor as smaller cats such as leopard cat were recorded frequently.

We recorded c. $75 \%$ of the felid species of Peninsular Malaysia in Jerangau Forest Reserve, even though the 
area has a history of logging and land use change over the last 30 years. However, the long-term survival of these species in this area is not guaranteed as these forested areas may not remain protected; logging in the area is a major revenue for the State. To sustain viable populations of felids the availability of forest cover and prey species are important (Nowell \& Jackson, 1996). Except for a few parks and reserves almost all lowland dipterocarp forest has been converted or logged in Peninsular Malaysia (Aiken \& Leigh, 1985). It is thus vital to understand whether secondary forest is able to support viable populations of these felid species. In addition, it is necessary to understand the species' ecological requirements if wildlife corridors are going to be established through altered habitat and agricultural land.

Our findings indicate that secondary forests in Peninsular Malaysia may be important for long-term conservation of felids. The presence of charismatic flagship species such as tiger in this unprotected lowland dipterocarp secondary forest will be of help to local conservation organizations and the Wildlife Department in any proposals for the protection of these areas.

\section{Acknowledgements}

We would like to thank the Department of Wildlife and National Parks of Peninsular Malaysia, Department of Forestry, FELDA Management, and all the other government agencies that provided help during this project. This was a WWF Malaysia project on tiger-human conflict resolution (MY 0086), funded by WWF UK and WWF Japan. We are grateful to Raleigh International (Malaysian Chapter), En Mat Salleh, FELDA Jerangau Barat settlers, and volunteers for their help with fieldwork. We would also like to thank G.W.H. Davison for his helpful comments and Kae Kawanishi for her encouragement and critical reviews of this manuscript. This article also benefitted from the useful comments of two anonymous reviewers.

\section{References}

Aiken, R.S. \& Leigh, C.H. (1985) On the declining fauna of Peninsular Malaysia in the post-colonial period. Ambio, 14, 15-22.

Anon (2000) Department of Forestry, Peninsular Malaysia. Annual Report 2000. Kuala Lumpur, Malaysia.

Bezuijen, M.R. (2003) The flat headed cat in the Merang river region of south Sumatra. Cat News, 38, 26-27.

Ellagupillay, S. (1984) Territorial range of an adult tigress at Behrang Ulu Cattle Farm. Journal of Wildlife and Parks, 3, 63-67.

Franklin, N., Bastoni, S., Siswomartono, D., Manansang, J. \& Tilson, R. (1999) Last of the Indonesian tigers: a cause for optimism. In Riding the Tiger: Tiger Conservation in Human-dominated Landscapes (eds J. Siedensticker, S. Christie
\& P. Jackson), pp. 130-147. Cambridge University Press, Cambridge, UK.

Jackson, P. (1983) The tragedy of our tropical rainforests. Ambio, 12, 252-254.

Jasmi, A. (1998) The distribution and management of the Malayan tiger, Panthera tigris corbetti in Peninsular Malaysia. Unpublished paper presented at the Year of the Tiger Conference, February 1998, Dallas, USA.

Karanth, K.U. (1995) Estimating tiger Panthera tigris populations from camera-trap data using capture-recapture models. Biological Conservation, 71, 333-338.

Karanth, K.U. \& Nichols, J.D. (1998) Estimation of tiger densities in India using photographic captures and recaptures. Ecology, 79, 2852-2862.

Kawanishi, K. (2002) Population status of tigers (Panthera tigris) in a primary rainforest of Peninsular Malaysia. PhD thesis. University of Florida, Gainesville, USA.

Kawanishi, K., Sahak, A.M. \& Sunquist, M. (1999) Preliminary analysis on abundance of large mammals at Sungai Relau, Taman Negara. Journal of Wildlife and National Parks, 17, 62-82.

Kawanishi, K. \& Sunquist, M. (2003) Possible new records of fishing cat from Peninsular Malaysia. Cat News, 39, 3-5.

Kawanishi, K. \& Sunquist, M. (2004) Conservation status of tigers in a primary rainforest of Peninsular Malaysia. Biological Conservation, 120, 329-344.

Khan, M.K. (1987) Tigers in Malaysia: prospects for the future. In Tigers of the World: The Biology, Biopolitics, Management and Conservation of an Endangered Species (eds. R.L. Tilson \& U.S. Seal), pp. 75-84. Noyes Publications, Park Ridge, USA.

Lim, B.L. (1999) The distribution, food habits and parasite patterns of the leopard cat (Prionailurus bengalensis) in Peninsular Malaysia. Journal of Wildlife and National Parks, $17,17-27$.

Lim, B.L. (2002). Distribution and food habits of the golden cat (Catopuma temmincki) in Peninsular Malaysia. Journal of Wildlife and National Parks, 20, 43-48.

McDougal, C. (1977) The Face of the Tiger. Rivington Books, London, UK.

Medway, L. (1983) The Wild Mammals of Malaya (Peninsular Malaysia) and Singapore. 2nd edition. Oxford University Press, Kuala Lumpur, Malaysia.

Mohd. Azlan, J. \& Sharma, D.S.K. (2001) Annual Report: Tiger Human Conflict Resolution in Peninsular Malaysia, 2000. Unpublished Report. WWF Malaysia, Petaling Jaya, Malaysia.

Mohd. Azlan, J. \& Sharma, D.S.K. (2003). Camera trapping the Indochinese Tiger (Panthera tigris corbetti) in a Secondary Forest, Peninsular Malaysia, Raffles Bulletin of Zoology, 51, 421-427.

Nowell, K. \& Jackson, P. (1996) Wild Cats: Status Survey and Conservation Action Plan. IUCN, Gland, Switzerland.

Payne, J., Francis, C.M. \& Phillipps, K. (1985) A Field Guide to the Mammals of Borneo. The Sabah Society, Kota Kinabalu, Malaysia.

Rabinowitz, A.R. (1989) The density and behavior of large cats in a dry tropical forest mosaic in Huai Kha Khaeng Wildlife Sanctuary, Thailand. Natural History Bulletin of the Siam Society, 37, 235-251.

Rabinowitz, A., Andau, P. \& Chai, P.P.K. (1987) The clouded leopard in Malaysian Borneo. Oryx, 21, 107-111.

Rajanathan, R. (2000) Ecology of the leopard cat (Prionailurus bengalensis) in Tabin Wildlife Reserve, Sabah, Malaysia. $\mathrm{PhD}$ thesis, Faculty of Science \& Technology, University Kebangsaan, Malaysia. 
Rajaratnam, L.K. (1999) Non-volant small mammals in Tabin Wildlife Reserve, Sabah, Malaysia. MSc thesis, University of New England, Armidale, Australia.

Schaller, G.B. (1967) The Deer and the Tigers: A Study of Wildlife in India. University of Chicago Press, Chicago, USA.

Seidensticker, J. (1976) On the ecological separation between tigers and leopards. Biotropica, 8, 225-234.

Sunquist, M. \& Sunquist, F. (2002) Wild Cats of the World. The University of Chicago Press, Chicago, USA.

Symington, C.F. (1974) Foresters' Manual of Dipterocarps: Malaysian forest record no. 16. University of Malaya Publication, Kuala Lumpur, Malaysia.

Topani, R. (1990) Status and distribution of tiger in Peninsular Malaysia. Journal of Wildlife and Parks, 9, 71-102.

Whitmore, T.C. (1975) Tropical Rain Forest of the Far East. Clarendon Press, Oxford, UK.

\section{Biographical Sketches}

Mohd. Azlan J. worked on tiger-human conflict in Peninsular Malaysia from 2000 to 2002 and is currently attached to Animal Science and Resource Management, Faculty of Resource Science and Technology, UNIMAS, Sarawak, carrying out research on the distribution of felids in Sarawak.

Dionysius S.K. Sharma has been working in conservation for the past 15 years with WWF Malaysia, and is currently the National Program Director. His particular interests are in vertebrate ecology, especially freshwater and marine turtles and tigers. 